\title{
Consumer preference for energy, fat, salt and ingredient information in catering outlets
}

\author{
D. Mackison ${ }^{1}$, A. S. Anderson ${ }^{1}$ and W. L. Wrieden ${ }^{2}$ \\ ${ }^{1}$ Centre for Public Health Nutrition Research, University of Dundee, Dundee DD1 9SY, UK and ${ }^{2}$ Health Services Research \\ Unit, University of Aberdeen, Aberdeen AB25 2ZD, UK
}

Eating outside the home has been associated with increased energy intake and decreased physical activity ${ }^{(1)}$. It is reported that American consumers are unable to determine the energy and fat content of restaurant meals ${ }^{(2)}$. As energy information becomes mandatory in chain restaurants in New York State ${ }^{(3)}$ it becomes clear that very little is known about British consumers' views on healthy eating choices outside the home and their preference for nutritional information in catering establishments. The present study examines the British consumers' preference for information on energy, fat, salt and ingredients at popular catering outlets.

A short postal survey assessing frequency of dining out, 'motivation to eat a healthy diet' and desire to see energy, fat, salt and ingredient information at different venues was distributed to a sample representative of gender, age and country of residence for the UK population. Cross-tabulations and the $\chi^{2}$ test for independence were calculated to test within-group differences for selected demographics with frequency of dining and desire to request energy, fat, salt and ingredient information at specific catering outlets. Completed responses were obtained for 786 adults ( $35.5 \%$ male, $64.5 \%$ female) aged $\geq 18$ years from a range of social backgrounds (response rate $16.4 \%$ ).

The majority of consumers $(75.3 \%)$ reported eating at a catering outlet at least once per month, with take-away and sandwich outlets the most frequently visited. Socio-demographic characteristics were associated with dining frequency; males were more likely to frequent take-away outlets $(P<0.001)$, sandwich outlets and canteens $(P<0.05)$ compared with females. Information on ingredients and salt were desired by the majority of consumers at all outlets (Table).

\begin{tabular}{|c|c|c|c|c|c|c|}
\hline & \multicolumn{6}{|c|}{ Percentage of sample } \\
\hline & $\begin{array}{l}\text { Sandwich outlets } \\
(n \text { 783) }\end{array}$ & $\begin{array}{l}\text { Canteens } \\
(n 782)\end{array}$ & $\begin{array}{l}\text { Fast-food outlets } \\
(n \text { 783) }\end{array}$ & $\begin{array}{c}\text { Take-away outlets } \\
(n \text { 783) }\end{array}$ & $\begin{array}{l}\text { Pubs } \\
(n 782)\end{array}$ & $\begin{array}{c}\text { Restaurants } \\
\quad(n \text { 783) }\end{array}$ \\
\hline Ingredient & 65.2 & 58.1 & 63.6 & 61.6 & 54.8 & 55.4 \\
\hline Salt & 60.2 & 51.5 & 60.8 & 56.7 & 49.9 & 50.3 \\
\hline Fat & 57.6 & 50.6 & 59.1 & 55.6 & 47.4 & 48.8 \\
\hline Energy & 55.9 & 47.2 & 52.1 & 48.0 & 42.3 & 42.7 \\
\hline
\end{tabular}

Most consumers reported a desire to see information on fat at fast-food, take-away and sandwich outlets and canteens. Desire to see energy, fat, salt and ingredient information was lower at pubs and restaurants than in the other catering outlets surveyed. Motivated participants (compared with less-motivated participants) were significantly more likely to seek energy (except in pubs), fat, salt and ingredient information in all outlets $($ all $P<0.05)$. Females were significantly more likely to want to see information on energy at all outlets in comparison with male participants (for sandwich, fast-food and take-away outlets $P<0.001$; for canteens, pubs and restaurants $P<0.05$ )

In conclusion, British consumers are interested in obtaining energy, fat and ingredient information at catering outlets and further research should address the practical implications.

This work was funded by the Food Standards Agency Postgraduate Scholarship Scheme. Any views expressed are the authors own.

1. Orfanos P, Naska A, Trichopoulos D et al. (2007) Public Health Nutr 10, 1515-1525.

2. Burton S, Creyer EH, Kees J et al. (2006) Am J Public Health 96, 1669-1675.

3. New York City Department of Health and Mental Hygiene (2007) New York City Health Code (Repeal and reenact 81.50) http://www.nyc.gov/html/ $\mathrm{doh} /$ downloads/pdf/public/notice-intention-hc-art81-50-1007.pdf 